\title{
Multi-Residue Method for Determination of Thirty-Five Pesticides, Pharmaceuticals and Personal Care Products in Water Using Ionic Liquid-Dispersive Liquid-Liquid Microextraction Combined with Liquid Chromatography-Tandem Mass Spectrometry
}

\author{
Liziane C. Marube, Sergiane S. Caldas, Elisane O. dos Santos, Andressa Michaelsen \\ and Ednei G. Primel**
}

\author{
Escola de Química e Alimentos, Universidade Federal do Rio Grande (FURG), \\ 96203-900 Rio Grande-RS, Brazil
}

\begin{abstract}
Ionic liquid-dispersive liquid-liquid microextraction (IL-DLLME) was used for the determination of different chemical classes of analytes for the first time. Limits of quantification (LOQs) ranged from 0.5 to $2.5 \mu \mathrm{g} \mathrm{L}^{-1}$, and the linearity ranged from the LOQ of each compound to $50 \mu \mathrm{g} \mathrm{L}^{-1}$. Recoveries ranged from 70 to $120 \%$ for the compounds, with relative standard deviations less than $18 \%$. The proposed method demonstrates for the first time that sample preparation by IL-DLLME and determination by liquid chromatography-tandem mass spectrometry (LC-MS/MS) can be used successfully for the simultaneous extraction of 19 kinds of pesticides and 16 PPCPs from water samples. In addition, to eliminate the environmental risk of waste solvent disposal, this technique uses a low-toxicity extraction solvent. Finally, the analytical method proposed was applied successfully in analysis in surface water samples.
\end{abstract}

Keywords: IL-DLLME, water, pesticides, PPCPs, LC-MS/MS

\section{Introduction}

In recent decades, many synthetic organic compounds detected in water samples have attracted people's attention. Pesticides, pharmaceuticals and personal care products $(\mathrm{PPCPs})^{1}$ have also been detected and are investigation targets. $^{2}$

Pesticides play an important role in increasing agricultural productivity. Their use in agriculture is inevitable, still being the most effective tool in the fight against weeds and pests. They are not only used for agricultural purposes, but also in forest and environmental preservation areas. Although the use of pesticides in agricultural applications provides a wide range of beneficial effects, their extensive use has been a concern because of hazards to the environment. ${ }^{1,3}$ Toxic effects on humans, such as acute neurological toxicity, impairment of neurological development, possible dysfunction of the immune, reproductive and endocrine systems, cancers, chronic kidney disease and other potential diseases have been reported in many papers. ${ }^{4,5}$

*e-mail: eprimelfurg@gmail.com
PPCPs are used to prevent or treat human and animal diseases or to improve the quality of daily life. They have emerged as a major group of environmental pollutants over the past decades since some of them are produced and used in large quantities. ${ }^{2}$ Various investigations indicate that many of them can hardly be totally removed during the water treatment process. Many PPCPs are persistent or pseudo-persistent in the environment and are toxic to non-target organisms. They also have the potential to bioaccumulate in different trophic level organisms. ${ }^{2,6}$

To quantitatively evaluate the fate of these chemicals and ensure the quality of drinking water, effective analytical methods are extremely necessary. Since the concentrations of pesticides and PPCPs in water are generally very low (ng L ${ }^{-1}$ or less), extraction techniques are needed prior to chromatographic determination. ${ }^{7}$ The most commonly used methods are liquid-liquid extraction (LLE), ${ }^{8,9}$ and solid phase extraction (SPE). ${ }^{10,11}$ These techniques, however, are time consuming and use large amounts of organic solvents. Thus, the need for lower solvent consumption and faster sample preparation has aroused the interest of miniaturization in analytical chemistry. ${ }^{12}$ In this context, two most common SPE miniaturization 
techniques are solid phase microextraction (SPME) $)^{13,14}$ and stir-bar sorptive extraction (SBSE) ${ }^{15,16}$ In addition to reducing the extraction time, they use little or no organic solvent, when coupled to thermal desorption (TD), and need minimal sample manipulation. Even so, the main disadvantages of these two techniques is the high price due to the limited lifetime of the fibers and carryover problems requiring time consuming cleaning procedures of the extraction devices. ${ }^{12}$ Therefore, new extraction techniques have been proposed in order to reduce the extraction time and solvent consumption.

In 2006, a microextraction technique known as dispersive liquid-liquid microextraction (DLLME) was applied for the first time for the determination of polycyclic aromatic hydrocarbons in water samples, using gas chromatography-flame ionization detection (GC-FID). ${ }^{17}$ This technique uses an extraction solvent which is immiscible in the aqueous phase, and a disperser solvent which is miscible in both the extraction solvent (organic phase) and the sample (aqueous phase). The solvent mixture is rapidly injected into the sample using a syringe, wherein the disperser solvent promotes the dispersion of the organic phase (extraction solvent) in the form of microdroplets in the aqueous sample. ${ }^{18}$ This technique uses a very small amount of extraction solvent and the surface contact between the two phases is infinitely large, leading to high enrichment factors and short extraction times. ${ }^{17}$ Speed, simplicity, low cost and effectiveness are the main advantages of this technique. ${ }^{12,19}$ In its original form, DLLME uses chlorinated solvents as extraction solvents, because of high density and immiscibility in water, thereby facilitating the separation of the phases after centrifugation. ${ }^{17}$ Chlorobenzene, carbon tetrachloride, chloroform, dichloromethane, and tetrachloroethylene are among the most commonly used chlorinated solvents, which are highly toxic and are not environmentally friendly. ${ }^{1}$

The implementation of processes without the use of organic solvents is ideal, however, they are almost inevitable due to their crucial role in the liquid-liquid microextraction. Some strategies have been proposed to minimize this problem; these include the replacement of petroleum solvents by others obtained from renewable resources and replacement of toxic solvents by solvents less toxic to both the environment and to the analyst. ${ }^{20}$ In order to lower the toxicity of the waste generated in the technique, as well as the exposure to toxic solvents by the analyst, other alternative extraction solvents such as ionic liquids (ILs) began to be employed in the technique. ${ }^{21,22}$

Ionic liquids have been employed in DLLME as extraction solvents resulting in the IL-DLLME technique.
ILs are defined as organic salts which are liquid at low temperatures $\left(<100^{\circ} \mathrm{C}\right)$. They stand out, not only for their potential as 'green' liquids, but also because they are not flammable, presenting high thermal stability, negligible vapor pressure, high viscosities, ionic conductivity and electrochemical and thermal stability moderate dissolvability in organic compounds, adjustable miscibility and polarity, as well as good extractability for different organic and inorganic compounds, as well as good solvation ability characteristics that make them a strong solvent extractor in microextraction. ${ }^{23,24}$ Among the most used are 1-hexyl-3-methylimidazolium hexafluorophosphate $\left[\mathrm{C}_{6} \mathrm{MIM}\right]\left[\mathrm{PF}_{6}\right]^{25}$ and 1-octyl-3-methylimidazolium hexafluorophosphate $\left[\mathrm{C}_{8} \mathrm{MIM}\right]\left[\mathrm{PF}_{6}\right] .{ }^{26}$ The use of ILs as extraction solvents was first reported by Zhou et al. ${ }^{27}$ during the determination of organophosphorus pesticides in water samples and has been applied for the extraction of different analytes groups such as in the ultrasound-assisted ionic liquid microextraction, ${ }^{26}$ vortex-assisted ionic liquid microextraction ${ }^{1}$ and microwave-assisted ionic liquid microextraction. ${ }^{28}$

Although DLLME has been widely applied in the determination of organic compounds in aqueous samples, IL-DLLME has never been applied in the simultaneous analysis of pesticides and PPCPs in water samples. In this study, IL-DLLME, a simple, green and rapid technique was successfully applied for simultaneous extraction of 19 pesticides and 16 PPCPs in water samples followed by determination with liquid chromatography tandem mass spectrometry with an electrospray ionization source (LC-ESI-MS/MS). To the best of our knowledge, there are limited reports on the application of IL-DLLME in the extraction of different classes of organic compounds in water samples.

\section{Experimental}

\section{Reagents}

Amitriptyline, furosemide and mebendazole were bought from United States Pharmacopeia (USP, USA). Albendazole, carbamazepine, diltiazem hydrochloride, gemfibrozil, glibenclamide, haloperidol, miconazole nitrate, nimesulide, nifepidine and propylparaben were provided by Fiocruz (Oswaldo Cruz Foundation, Brazil). Bisphenol-A, azoxystrobin, carbofuran, carbofuran- $d_{3}$ cyproconazole, clomazone, dichloran, diuron, diuron- $d_{6}$, difenoconazole, fenoxaprop-p-ethyl, fipronil, irgarol, iprodione, malathion, pyraclostrobin, propanil, propiconazole, tebuconazole and trifloxystrobin were bought from Sigma-Aldrich (Brazil). Triclocarban, triclosan, epoxiconazole and 
penoxsulam were supplied by Dr. Ehrenstofer $\mathrm{GmbH}$ (Germany). Magnesium sulfate (anhydrous, $\mathrm{MgSO}_{4}$ ) was purchased from J.T.Baker (Mexico) and ammonium sulfate $\left(\left(\mathrm{NH}_{4}\right)_{2} \mathrm{SO}_{4}\right)$ was provided by Synth (Brazil). Glacial acetic acid and hydrochloridric acid were obtained from Merck (Germany). All analytical standards and reagents were of high purity ( $>98 \%$ ). The water was purified by an Ultrapure Water System (USA).

\section{Standard and sample preparation}

The individual stock standard solutions were prepared in methanol at a concentration of $1000 \mathrm{mg} \mathrm{L}^{-1}$. The working standard solutions were prepared at $5.0 \mathrm{mg} \mathrm{L}^{-1}$ by mixing the appropriate amounts of the individual standard solutions and diluting them with methanol. The standard surrogate was prepared at $100 \mathrm{mg} \mathrm{L}^{-1}$ in methanol. All solutions were kept at $-18{ }^{\circ} \mathrm{C}$. For validation and optimization of the method, tap water from the laboratory was used. For the method applicability, surface water samples were collected and analyzed immediately. Throughout the extraction optimization process, analyses of blank samples of tap water were performed to verify contamination in the extraction process.

\section{Apparatus and software}

The LC-MS/MS was performed, as described by Caldas et al., ${ }^{7}$ using a Waters Alliance 2695 Separations Module (Waters, Milford, MA, USA) fitted with an autosampler, a membrane degasser and a quaternary pump. Mass spectrometry was performed with a Micromass Quattro Micro API (Waters, Milford, MA, USA) with an electrospray (ESI) interface. Nitrogen, as both drying and nebulizing gas, was generated by pressurized air in a Genius NM32LA nitrogen generator (Peak Scientific). The nebulizing gas flow was $50 \mathrm{~L} \mathrm{~h}^{-1}$ whereas the desolvation gas flow was $550 \mathrm{~L} \mathrm{~h}^{-1}$. To operate in the MS/MS mode, the collision gas was argon $99.99 \%$ (White Martins, Brazil) with a pressure of $3.5 \times 10^{-3}$ mbar in the collision cell. The optimized values were as follows: capillary voltage, $4.0 \mathrm{kV}$; extractor voltage, $2 \mathrm{~V}$; source temperature, $100{ }^{\circ} \mathrm{C}$; desolvation temperature, $400{ }^{\circ} \mathrm{C}$; and multiplier, $650 \mathrm{~V}$. For each compound, optimum collision energies, which aimed at getting two characteristic multiple reaction monitoring (MRM) transitions with the best signal intensity were selected. After the optimization of the collision cell energy of the triple quadrupole, two different precursor ion-product ion transitions for quantification and confirmation were selected for each analyte. Table S1 (Supplementary Information) shows the optimized MRM transitions for the PPCPs and pesticides with their octanol-water partition coefficient (log KOW). Analytical instrument control and data acquisition and treatment were performed by the software MassLynx (Micromass, Manchester, UK), version 4.1. The chromatographic separation was performed by a Kinetex C8 column $(3.0 \times 50 \mathrm{~mm}$ i.d., $2.6 \mu \mathrm{m}$ film thickness, Phenomenex, USA). The mobile phase components were: (A) ultrapure water with $0.1 \%$ acetic acid and (B) methanol, with elution in the gradient mode. The initial composition was $20 \% \mathrm{~B}$; linearly increasing to $90 \%$ in $20 \mathrm{~min}$, held until $23 \mathrm{~min}$ and, then, returned to the initial composition $(20 \% \mathrm{~B})$ in $0.5 \mathrm{~min}$ and held for $6.5 \mathrm{~min}$, the total analytical time was $30 \mathrm{~min}$. The flow rates were as follows: $0-20 \mathrm{~min}, 0.2-0.4 \mathrm{~mL} \mathrm{~min}^{-1}$; 20-23 min, $0.4 \mathrm{~mL} \mathrm{~min}^{-1}$; 23-23.5 min, 0.4-0.2 $\mathrm{mL} \mathrm{min}^{-1}$; 23.5-30 min, $0.2 \mathrm{~mL} \mathrm{~min}^{-1}$. The injection volume was $10 \mu \mathrm{L}$.

\section{Selection of analytes}

In order to verify the feasibility of using the IL-DLLME technique for the extraction of multiclass analytes in water samples, a large number of analytes of a wide range of polarity were selected (Table S1, Supplementary Information). For the selection of the pesticides studied, a review was carried out on the most widely used pesticides in rice irrigation, which is prevalent in the southern region of the state of Rio Grande do Sul. Pesticides such as clomazone, carbofuran, epoxiconazole, diuron, tebuconazole among others have been widely detected in surface and treated waters in this region. ${ }^{29}$ The selected PPCPs have been detected in environmental samples in Brazil and around the world. ${ }^{29,30}$

\section{IL-DLLME}

$10 \mathrm{~mL}$ of an aqueous sample was put in a $15 \mathrm{~mL}$ glass tube and the $\mathrm{pH}$ value was adjusted to 4 . The standard surrogate $\left(25 \mu \mathrm{L}\right.$ of a $10 \mathrm{mg} \mathrm{L}^{-1}$ carbofuran- $d_{3}$ and diuron- $d_{6}$ standard) was also added to the samples. A mixture of $500 \mu \mathrm{L}$ of methanol (as disperser solvent) and $100 \mu \mathrm{L}$ of $\left[\mathrm{C}_{6} \mathrm{MIM}\right]\left[\mathrm{PF}_{6}\right]$ (as extraction solvent) was rapidly injected into the water sample with a syringe. The rapid and strong injection of the extraction mixture produced a cloudy solution sample after which it was centrifuged for $10 \mathrm{~min}$ at $4000 \mathrm{rpm}$. The sedimented phase $(90 \mu \mathrm{L})$ was withdrawn using $100 \mu \mathrm{L}$ microsyringe. Prior to LC-MS/MS analysis, the extraction solvent was mixed with methanol to a volume of $500 \mu \mathrm{L}$ to compensate for the high viscosity of the extraction solvent, and $10 \mu \mathrm{L}$ of the mixture was then injected into the chromatograph. In all steps of the optimization procedure, the standard surrogate was added 
and the recoveries ranged from 70 to $100 \%$ with relative standard deviations of less than $14 \%$.

\section{Validation experiments and internal quality control criteria}

The method was validated based on the procedure described by SANTE $^{31}$ and INMETRO ${ }^{32}$ and was performed using samples of tap water. To ensure the quality of the results, some internal quality criteria, which comprise the analyses of laboratory blanks (solvent blank) and laboratory control samples, were applied. When the reagents were used, background levels of analytes were below the detection limits. Furthermore, the daily set of samples under analysis was processed together with a blank extract that eliminated a false positive due to contamination in the extraction process, instrument or chemicals. Calibration curves were prepared daily in blank matrix extracts to check both sensitivity and linearity in the working range of concentrations. Thus, quantification mistakes caused by possible matrix effects of instrumental fluctuations could be avoided.

Limits of detection (LOD) and quantification (LOQ) were calculated based on the signal-to-noise ratio $(\mathrm{S} / \mathrm{N})$ of individual peaks, assuming a ratio of 3:1 for LODs and 10:1 for LOQs. Resulting values were also experimentally checked. Recovery was determined at least in three levels and in three replicates. Calculations of recoveries were carried out by using the peak areas according to the following equation: recovery $(\%)=[(\mathrm{C} 1-\mathrm{C} 2) / \mathrm{C} 3] \times 100$, where $\mathrm{C} 1$ is the concentration of the analyte in the final extract, $\mathrm{C} 2$ is the concentration of the analyte in the blank sample and $\mathrm{C} 3$ is the concentration of the analyte added to the sample. Precision was calculated as the relative standard deviation (RSD) for each concentration level. The linearity of the instrumental analytical curves was evaluated at a concentration range from the LOQ to $1000 \mu \mathrm{g} \mathrm{L}^{-1}$ by at least five calibration solutions prepared in blank control sample extracts and in the solvent. Overall IL-DLLME linearity was also investigated by using water samples fortified in a range from the LOQ to $50 \mu \mathrm{g} \mathrm{L}^{-1}$. The matrix effect (ME) was also investigated, since it has an important effect on LC-MS/MS, generating erroneous decisions by either suppression or enhancement of the signal. The ME was evaluated by comparing the calibration curves prepared in the solvent and in the matrix. The matrix effects were determined according to the slopes of the calibration curves of the matrix extract and solvent. In general, ME values of around $\pm 20 \%$ were considered low; ranges of $-50 \%<\mathrm{ME}<-20 \%$ or $+20 \%>\mathrm{ME}>+50 \%$ were medium; and high when either lower than $-50 \%$ or higher than $+50 \%$. $^{33}$

\section{Results and Discussion}

\section{Selection of extraction and disperser solvent}

The selection of the ionic liquid to be used as extractor is determined by several requirements: it must be immiscible in the aqueous sample, high capacity to extract organic compounds, higher density than water and compatible with the detection method, in this case was liquid chromatography. As a result, the imidazolium ionic liquids containing $\left[\mathrm{PF}_{6}\right]$ with an alkyl side hydrophobic chain $\left(\left[\mathrm{C}_{\mathrm{n}} \mathrm{MIN}\right]\left[\mathrm{PF}_{6}\right]\right.$, $n=4,6$ and 8) are prevalent among extraction solvents in liquid-liquid microextractions. ${ }^{34}$ Table S2 (Supplementary Information) shows the physicochemical properties of the ILs used in the present study.

Thus, in this study, $\left[\mathrm{C}_{4} \mathrm{MIM}\right]\left[\mathrm{PF}_{6}\right]$ and $\left[\mathrm{C}_{6} \mathrm{MIM}\right]\left[\mathrm{PF}_{6}\right]$ were evaluated as extraction solvents, while methanol, acetonitrile and acetone were evaluated as disperser solvents. All combinations of extractor and disperser solvents were tested to evaluate the efficiency of extraction. The combinations of $\left[\mathrm{C}_{4} \mathrm{MIM}\right]\left[\mathrm{PF}_{6}\right]$ with the dispersing solvents resulted in the formation of a small cloudy solution leading to little or no formation of the sedimented organic phase after centrifugation due to its high solubility in water. Similar behavior was observed by Suárez et al..$^{23}$ and Zhang et al. ${ }^{34,35}$ Therefore, $\left[\mathrm{C}_{4} \mathrm{MIM}\right]\left[\mathrm{PF}_{6}\right]$ was eliminated.

As it can be seen in Figure S1 (Supplementary Information), when $\left[\mathrm{C}_{6} \mathrm{MIM}\right]\left[\mathrm{PF}_{6}\right]$ was used, combined with acetone and acetonitrile as disperser solvents, recoveries decreased for all compounds. However, when acetonitrile was used as the disperser solvent, the solution remained cloudy even after centrifuging and a small volume of the sedimented phase was observed at the bottom of the tube, resulting in lower recoveries. This is because acetonitrile leaves $\left[\mathrm{C}_{6} \mathrm{MIM}\right]\left[\mathrm{PF}_{6}\right]$ very miscible in water. Therefore, acetonitrile was not a suitable solvent for the extraction of analytes. In the determination of four heterocyclic insecticides in water samples using IL-DLLME, Liu et al. ${ }^{25}$ observed the same behavior. As it can be seen, methanol exhibits better recoveries for all compounds, thus it was selected as the disperser solvent.

A statistical test was conducted to evaluate whether there were significant differences between the values in the evaluation area of the mixture of $\left[\mathrm{C}_{6} \mathrm{MIM}\right]\left[\mathrm{PF}_{6}\right]$ with the disperser solvent. When $\left[\mathrm{C}_{6} \mathrm{MIM}\right]\left[\mathrm{PF}_{6}\right]$ was used as the extraction solvent and methanol as the dispersing solvent, a large number of compounds with significantly greater areas $(p<0.05)$ was found. Considering the results, $\left[\mathrm{C}_{6} \mathrm{MIM}\right]\left[\mathrm{PF}_{6}\right]$ and methanol were chosen.

The combination of the extractor ionic liquid $\left[\mathrm{C}_{6} \mathrm{MIM}\right]\left[\mathrm{PF}_{6}\right]$ and methanol has also been used in other 
studies for determining inseticides, ${ }^{25}$ anthraquinones ${ }^{36}$ and flame retardants in water samples ${ }^{37}$ and pesticides in bananas ${ }^{38}$ grapes and plums. ${ }^{19}$

\section{Extraction solvent volume optimization}

In microextraction techniques that use ionic liquids as extraction solvents, extraction volumes between $40-280 \mu \mathrm{L}$ are normally used.22

In order to evaluate the effect of the extraction solvent volume on the recovery of analytes, $500 \mu \mathrm{L}$ of methanol containing different amounts of $\left[\mathrm{C}_{6} \mathrm{MIM}\right]\left[\mathrm{PF}_{6}\right](75,100$, and $150 \mu \mathrm{L}$ ) were tested.

The results are shown in Figure S2 (Supplementary Information). When the volume of $75 \mu \mathrm{L}$ was used, recovery was low for most compounds. This is due to the fact that smaller extraction solvent volumes bring an incomplete dispersion of the extraction solvent in the aqueous sample. ${ }^{39}$ With the increase in the volume of $\left[\mathrm{C}_{6} \mathrm{MIM}\right]\left[\mathrm{PF}_{6}\right]$ from 75 to $100 \mu \mathrm{L}$, the recovery increased for all compounds. However, when increasing from 100 to $150 \mu \mathrm{L}$, a decrease occurs in the recoveries. A likely explanation for this would be that larger amounts of the extraction solvent decrease the polarity of the aqueous sample due to dissolution of the extraction solvent in the aqueous phase which leads to a decrease in the partition coefficient of analytes which can lead to decreased recoveries. ${ }^{40}$

A statistical test was performed to evaluate if there were significant differences between the area values in the volume evaluation of $\left[\mathrm{C}_{6} \mathrm{MIM}\right]\left[\mathrm{PF}_{6}\right]$. There was a significant difference $(p<0.05)$ in the extraction solvent volume for all compounds. However, when the volume of $100 \mu \mathrm{L}$ of $\left[\mathrm{C}_{6} \mathrm{MIM}\right]\left[\mathrm{PF}_{6}\right]$ was used, a large number of compounds with significantly greater areas $(p<0.05)$ was found. For efficient extraction of analytes and high enrichment factors, to improve the sensitivity of the method, the volume should be chosen appropriately. Based on these, the volume of $100 \mu \mathrm{L}\left[\mathrm{C}_{6} \mathrm{MIM}\right]\left[\mathrm{PF}_{6}\right]$ was chosen.

\section{Disperser solvent volume optimization}

The disperser solvent volume directly affects the solubility of the IL in the aqueous sample and the volume of the sedimented phase. To evaluate the effect of the disperser solvent volume, volumes of 250,500 and $1500 \mu \mathrm{L}$ of methanol were tested with $100 \mu \mathrm{L}\left[\mathrm{C}_{6} \mathrm{MIM}\right]\left[\mathrm{PF}_{6}\right]$. As shown in Figure S3 (Supplementary Information), when the disperser volume increased from 250 to $500 \mu \mathrm{L}$, recovery increases for all analytes, but when the volume increased from 500 to $1500 \mu \mathrm{L}$, a decrease in recovery occurs for all analytes.
This is because smaller volumes of the disperser solvent may not be suitable for the dispersion of the extraction solvent in the aqueous sample, resulting in a small contact area between the aqueous sample and the solvents. Larger disperser solvent volumes, on the other hand, can increase the solubility of the analytes in the aqueous sample, thus hindering the partitioning of the analytes to the extraction solvent. ${ }^{41}$ This behavior was observed by Gure et al ${ }^{42}$ in the determination of sulfonylurea herbicides in wine using IL-DLLME. ${ }^{42}$

A statistical test was performed to find out if there were significant differences between the area values when evaluating the volume of methanol. There was a significant difference $(p<0.05)$ in the disperser solvent volumes used. However, when using the volume of $500 \mu \mathrm{L}$ of methanol, all compounds showed a significantly greater area $(p<0.05)$, therefore, the volume of $500 \mu \mathrm{L}$ of methanol was chosen. Studying pesticide extraction in water using IL-DLLME, Liu et al. ${ }^{25}$ also used a methanol volume of $500 \mu \mathrm{L}$.

\section{Effect of the sample $\mathrm{pH}$}

The $\mathrm{pH}$ of the sample plays an important role in extraction of pesticides and PPCPs. The $\mathrm{pH}$ of the sample determines how the analytes will be present in the sample (as ions or neutral), which can subsequently affect their recovery. ${ }^{36}$ Since most pesticides and PPCPs have ionizable functional groups, the $\mathrm{pH}$ of the aqueous sample has influence on the recovery of analytes, because charged species tend to avoid the organic solvent. ${ }^{43}$

The effect of $\mathrm{pH}$ was studied to evaluate the recovery of the analytes at $\mathrm{pH}$ values 2, 4 and 6.0 (the $\mathrm{pH}$ of tap water), through the addition of a phosphoric acid solution.

In Figure S4 (Supplementary Information), it can be seen that for the analytes albendazole ( $\left.\mathrm{p} K_{\mathrm{a}} 4.27\right)$, carbamazepine $\left(\mathrm{p} K_{\mathrm{a}} 3.8\right)$ and nifedipine $\left(\mathrm{p} K_{\mathrm{a}} 5.33\right)$, there is an increase in recovery of these compounds with a $\mathrm{pH}$ increase from 2.0 to 4.0. This same behavior was also observed in earlier studies using IL-DLLME for determination of drugs. ${ }^{44,45}$ For the pesticides, in general, it can be seen that with the increase of $\mathrm{pH}$ from 2 to 4 , there is an increase in the recovery for all compounds, but when increasing from $\mathrm{pH} 4$ to 6 there is a decrease in recovery for all compounds.

A statistical test was performed to evaluate if there were significant differences between the area values in the evaluation of $\mathrm{pH}$ of the sample. A significant difference $(p<0.05)$ was observed for most of the compounds except for iprodione and propanil. When sample $\mathrm{pH} 4$ was used, a large number of compounds with significantly greater areas $(p<0.05)$ was found. Since the objective was to 
choose a good condition to extract pesticides and PPCPs simultaneously, $\mathrm{pH} 4$ was thus selected.

\section{Effect of addition of salt}

The addition of salt generally decreases the solubility of the analytes in the aqueous sample and increases their partition into the organic phase. ${ }^{25}$ When salt is added to the solution, the water molecules form a hydration sphere around the ionic salt molecule. The hydration spheres reduce the amount of water available to dissolve the analytes favoring analyte extraction into the organic phase. This effect is mainly observed for analytes with high polarity. ${ }^{46}$

However, the addition of salt may have different effects when ionic liquids are used as extraction solvents. ${ }^{25}$ Generally, most studies use $\mathrm{NaCl}$ to investigate the influence of ionic strength on IL-DLLME. In this experiment, tests were carried without the addition of salt, with $1 \%(\mathrm{~m} / \mathrm{v})$ magnesium sulfate $\left(\mathrm{MgSO}_{4}\right)$ and $1 \%(\mathrm{~m} / \mathrm{v})$ ammonium sulfate $\left(\left(\mathrm{NH}_{4}\right)_{2} \mathrm{SO}_{4}\right)$ to evaluate the effect of different salts on the recoveries of analytes.

After addition of salt in the aqueous sample, the $\mathrm{pH}$ was adjusted to 4 . The addition of salts does not produce any significant difference $(p>0.05)$ for the compounds azoxystrobin, carbofuran, cyproconazole, difenoconazole, pyraclostrobin and propanil. However, for albendazole, diltiazem hydrochloride, furosemide, mebendazole, irgarol, diuron, and trifloxystrobin, the presence of salts resulted in a significant decrease $(p<0.05)$ in recoveries. For the other compounds, the option without salt had higher or similar recoveries with the presence of salt. Therefore according to Figure S5 (Supplementary Information), no salt was used in further experiments.

\section{Optimal conditions}

After the optimization, the optimal conditions for extraction were $10 \mathrm{~mL}$ of the sample of $\mathrm{pH} 4$, a mixture of $100 \mu \mathrm{L}$ of $\left[\mathrm{C}_{6} \mathrm{MIM}\right]\left[\mathrm{PF}_{6}\right]$ and $500 \mu \mathrm{L}$ of methanol that were injected quickly into the aqueous sample, forming a cloudy solution that was centrifuged at $4000 \mathrm{rpm}$ for $10 \mathrm{~min}$. The sedimented phase was collected with a syringe and placed in an Eppendorf, and the volume was incresead to $500 \mu \mathrm{L}$ with methanol.

\section{Method validation}

Calibration curves were prepared in the extract and solvent (Table 1). Correlation coefficients (r) ranging from 0.9914 to 0.9999 indicate excellent linearity for all compounds. The linearity of the method was evaluated using a procedural standard calibration in which the samples were spiked with a standard mixture containing all analytes in concentrations ranging from the limit of quantitation to $50 \mu \mathrm{g} \mathrm{L} \mathrm{L}^{-1}$. After fortification, each concentration was extracted and injected in triplicate into the chromatographic system, and all compounds showed a correlation coefficient of $r>0.99$, indicating good linearity of the method according to the validation directives. The LOQs vary from 0.5 to $2.5 \mu \mathrm{g} \mathrm{L}^{-1}$ for PPCPs and pesticides. The LODs ranged from 0.1 to $0.8 \mu \mathrm{g} \mathrm{L} \mathrm{L}^{-1}$ for PPCPs as well as pesticides. Pesticides had LOQs within the limit allowed by the $\mathrm{EU}^{47}$ for total pesticides $\left(0.5 \mu \mathrm{L} \mathrm{L}^{-1}\right)$ in water, except for difeconazole, fenoxaprop$p$-ethyl, irgarol, malathion, penoxulam, pyraclostrobin, propanil, propiconazole, tebuconazole, trifloxystrobin that had LOQs of $2.5 \mu \mathrm{g} \mathrm{L} \mathrm{L}^{-1}$. Regarding the Brazilian legislation for water potability, MS Ordinance No. $2914 / 2011,{ }^{48}$ which regulates 54 chemicals that pose risks to human health, 22 of which are pesticides, stipulates allowable maximum contamination level (MCL) ranges from 0.03 to $500 \mu \mathrm{g} \mathrm{L}^{-1}$.

The LOQs found in this study are within the allowed range. ${ }^{48}$ For PPCPs, there is still no regulation on MCL. Nevertheless, the values shown in Table 2 were similar or lower than the values obtained for other IL-DLLME applications. ${ }^{26,49,50}$

The accuracy of IL-DLLME was evaluated in terms of recovery, which ranged from 70 to $118 \%$ for repeatability (intra-day) and between 70 and $120 \%$ for the intermediate precision (inter-day) (Table 2). The precision of the method was expressed by the RSD sample of tap water spiked at three levels. The method showed good repeatability and intermediate precision with RSD values between 1-18\% and $2-18 \%$, respectively, in all fortification levels.

Albendazole, diltiazem hydrochloride, triclosan, carbofuran, azoxystrobin, clomazone, diuron and penoxsulam showed signal suppression matrix effect, the other analytes showed no matrix effect or had a small matrix effect. In other studies that evaluated the matrix effect in DLLME, the suppression effect was also observed for the analytes. ${ }^{7,51}$ To correct this effect, the analytes were quantified using the curve in the matrix.

\section{Applicability}

To evaluate the applicability of the IL-DLLME method, water samples were collected from Arroio Vieira stream (pH 6.6; turbidity 12 NTU), in April 2016. Quantification was performed by standard addition with 5 minimal concentration levels to compensate for any matrix effect. 
Table 1. Linear range, analytical curves in the solvent and in the extract, and the matrix effects

\begin{tabular}{|c|c|c|c|c|c|c|}
\hline Analyte & $\begin{array}{l}\text { Linear range / } \\
\qquad\left(\mu \mathrm{g} \mathrm{L}^{-1}\right)\end{array}$ & $\begin{array}{c}\text { Analytical curves in the } \\
\text { solvent }\end{array}$ & $\mathrm{r}$ & $\begin{array}{c}\text { Analytical curves in the } \\
\text { extract }\end{array}$ & $\mathrm{r}$ & $\mathrm{ME} / \%$ \\
\hline \multicolumn{7}{|c|}{ PPCP } \\
\hline Amitriptyline & $2.5-50$ & $y=105817 x-246.59$ & 0.9996 & $y=86525 x-1008.1$ & 0.9997 & -18 \\
\hline Albendazole & $2.5-50$ & $y=533150 x+6761.3$ & 0.9981 & $y=155409 x-2618.4$ & 0.9993 & -70 \\
\hline Bisphenol-A & $2.5-50$ & $y=1448.3 x+74.866$ & 0.9939 & $y=1315.4 x+27.958$ & 0.9988 & -9 \\
\hline Carbamazepine & $0.5-50$ & $y=284148 x+3244.7$ & 0.9993 & $y=228100 x-1040.7$ & 0.9991 & -19 \\
\hline Diltiazem hydrochloride & $2.5-50$ & $y=217669 x+1652.5$ & 0.9984 & $y=155905 x-4527.9$ & 0.9951 & -27 \\
\hline Furosemide & $2.5-50$ & $y=31920 x+159.1$ & 0.9997 & $y=26058 x-611.77$ & 0.9953 & -18 \\
\hline Gemfibrozil & $2.5-50$ & $y=21093 x+544.79$ & 0.9988 & $y=19173 x-155.03$ & 0.9996 & -9 \\
\hline Glibenclamide & $2.5-50$ & $y=47900 x+556.34$ & 0.9996 & $y=41530 x-765.79$ & 0.9993 & -13 \\
\hline Haloperidol & $2.5-50$ & $y=555340 x+14865$ & 0.9944 & $y=435016 x-2921.4$ & 0.9965 & -21 \\
\hline Mebendazole & $0.5-50$ & $y=295820 x+2374.8$ & 0.999 & $y=248359 x-1939.5$ & 0.9995 & -16 \\
\hline Miconazole & $0.5-50$ & $y=150768 x-761.35$ & 0.9994 & $y=147611 x-2460.8$ & 0.9989 & -2 \\
\hline Nifedipine & $2.5-50$ & $y=35851 x-875.21$ & 0.9965 & $y=35768 x-1456.7$ & 0.9917 & -2 \\
\hline Nimesulide & $2.5-50$ & $y=62516 x+5188$ & 0.9904 & $y=63877 x+1214.8$ & 0.9919 & -2 \\
\hline Propylparaben & $0.5-50$ & $y=37044 x+1353.2$ & 0.9931 & $y=30325 x+505.83$ & 0.9971 & -18 \\
\hline Triclocarban & $2.5-50$ & $y=105111 x+4158.3$ & 0.9981 & $y=99013 x-1463.3$ & 0.998 & -5 \\
\hline Triclosan & $2.5-50$ & $\mathrm{y}=1514.9 \mathrm{x}+3.5007$ & 0.9946 & $y=1085.4 x-13.272$ & 0.9997 & -28 \\
\hline \multicolumn{7}{|c|}{ Pesticide } \\
\hline Azoxystrobin & $0.5-50$ & $y=349993 x+1509.3$ & 0.9995 & $y=221454 x-5334.5$ & 0.9967 & -36 \\
\hline Carbofuran & $0.5-50$ & $y=284094 x+4283.7$ & 0.9986 & $y=169818 x+11.22$ & 0.9999 & -40 \\
\hline Cyproconazole & $0.5-50$ & $y=115826 x+106.26$ & 0.998 & $y=94030 x-325.98$ & 0.9997 & -18 \\
\hline Clomazone & $0.5-50$ & $y=449535 x+8023.8$ & 0.9986 & $y=344387 x-1801.7$ & 0.9994 & -23 \\
\hline Dichloran & $2.5-50$ & $y=1977 x+55.354$ & 0.9987 & $y=1496.8 x-16.029$ & 0.9995 & -22 \\
\hline Difenoconazole & $2.5-50$ & $y=303289 x+6291.5$ & 0.9995 & $y=265085 x-4726.5$ & 0.999 & -12 \\
\hline Diuron & $0.5-50$ & $y=44133 x+744.64$ & 0.9972 & $y=33791 x+41.586$ & 0.9997 & -23 \\
\hline Epoxyconazole & $0.5-50$ & $y=241974 x+2509.5$ & 0.9992 & $y=201343 x-2119.8$ & 0.9992 & -16 \\
\hline Fenoxaprop-p-ethyl & $2.5-50$ & $y=83721 x+2605.3$ & 0.9994 & $y=75106 x-1385.1$ & 0.9979 & -10 \\
\hline Fipronil & $0.5-50$ & $y=183647 x+2696.3$ & 0.9954 & $y=150456 x-864.97$ & 0.9996 & -18 \\
\hline Iprodione & $0.5-50$ & $y=47045 x+706.21$ & 0.9986 & $y=36848 x-490.24$ & 0.9993 & -21 \\
\hline Irgarol & $2.5-50$ & $y=1 \times 10^{6} x+3167.9$ & 0.9987 & $y=852511 x-23118$ & 0.9979 & -14 \\
\hline Malathion & $2.5-50$ & $y=228987 x+4467.7$ & 0.9972 & $y=197237 x-2374.1$ & 0.9914 & -13 \\
\hline Penoxsulam & $2.5-50$ & $y=10583 x+597.99$ & 0.9901 & $\mathrm{y}=7582.9 \mathrm{x}-72.213$ & 0.9999 & -28 \\
\hline Pyraclostrobin & $2.5-50$ & $y=111679 x+1530.2$ & 0.9996 & $y=91457 x-1483.5$ & 0.9975 & -18 \\
\hline Propanil & $2.5-50$ & $y=81483 x+5243.3$ & 0.994 & $y=72974 x-1866$ & 0.9958 & -10 \\
\hline Propiconazole & $2.5-50$ & $y=130660 x+1830$ & 0.9999 & $y=108460 x-876.93$ & 0.9999 & -16 \\
\hline Tebuconazole & $2.5-50$ & $y=125507 x+2530.7$ & 0.9989 & $y=101851 x-281.53$ & 0.9989 & -18 \\
\hline Trifloxystrobin & $2.5-50$ & $y=161855 x+3533.2$ & 0.9989 & $y=144828 x-2072.4$ & 0.9964 & -10 \\
\hline
\end{tabular}

PPCP: pharmaceuticals and personal care products; r: correlation coefficient; ME: matrix effect. 
Table 2. LOD and LOQ of the proposed method, recoveries and relative standard deviations in spiked drinking water samples

\begin{tabular}{|c|c|c|c|c|c|c|c|c|}
\hline \multirow{2}{*}{ Analyte } & \multirow{2}{*}{$\begin{array}{l}\mathrm{LOD} / \\
\left(\mu \mathrm{g} \mathrm{L}^{-1}\right)\end{array}$} & \multirow{2}{*}{$\begin{array}{l}\mathrm{LOQ} / \\
\left(\mu \mathrm{g} \mathrm{L}^{-1}\right)\end{array}$} & \multicolumn{3}{|c|}{ Repeatability (R \pm RSD) / \% } & \multicolumn{3}{|c|}{ Intermediate precision $(\mathrm{R} \pm \mathrm{RSD}) / \%$} \\
\hline & & & LOQ & $5 \mathrm{LOQ}$ & 10LOQ & LOQ & $5 \mathrm{LOQ}$ & $10 \mathrm{LOQ}$ \\
\hline \multicolumn{9}{|l|}{ PPCP } \\
\hline Amitriptyline & 0.8 & 2.5 & $95 \pm 6$ & $70 \pm 10$ & $75 \pm 5$ & $81 \pm 8$ & $73 \pm 7$ & $71 \pm 4$ \\
\hline Albendazole & 0.8 & 2.5 & $80 \pm 5$ & $116 \pm 7$ & $120 \pm 1$ & $75 \pm 8$ & $80 \pm 6$ & $76 \pm 5$ \\
\hline Bisphenol-A & 0.8 & 2.5 & $98 \pm 7$ & $75 \pm 8$ & $72 \pm 9$ & $76 \pm 10$ & $70 \pm 6$ & $72 \pm 9$ \\
\hline Carbamazepine & 0.1 & 0.5 & $115 \pm 2$ & $113 \pm 11$ & $70 \pm 7$ & $102 \pm 5$ & $95 \pm 3$ & $80 \pm 9$ \\
\hline Diltiazem hydrochloride & 0.8 & 2.5 & $80 \pm 7$ & $76 \pm 4$ & $85 \pm 15$ & $72 \pm 13$ & $82 \pm 9$ & $76 \pm 6$ \\
\hline Furosemide & 0.8 & 2.5 & $120 \pm 7$ & $109 \pm 6$ & $113 \pm 8$ & $82 \pm 7$ & $75 \pm 9$ & $98 \pm 11$ \\
\hline Gemfibrozil & 0.8 & 2.5 & $100 \pm 8$ & $80 \pm 1$ & $97 \pm 2$ & $76 \pm 3$ & $79 \pm 6$ & $74 \pm 7$ \\
\hline Glibenclamide & 0.8 & 2.5 & $84 \pm 2$ & $80 \pm 5$ & $70 \pm 8$ & $120 \pm 2$ & $87 \pm 7$ & $74 \pm 8$ \\
\hline Haloperidol & 0.8 & 2.5 & $120 \pm 3$ & $100 \pm 6$ & $120 \pm 10$ & $95 \pm 4$ & $80 \pm 6$ & $75 \pm 9$ \\
\hline Mebendazole & 0.1 & 0.5 & $120 \pm 7$ & $100 \pm 8$ & $100 \pm 5$ & $120 \pm 9$ & $105 \pm 5$ & $105 \pm 7$ \\
\hline Miconazole & 0.1 & 0.5 & $100 \pm 15$ & $120 \pm 5$ & $100 \pm 13$ & $100 \pm 9$ & $120 \pm 5$ & $100 \pm 9$ \\
\hline Nifedipine & 0.8 & 2.5 & $120 \pm 9$ & $110 \pm 8$ & $80 \pm 5$ & $110 \pm 6$ & $120 \pm 9$ & $110 \pm 6$ \\
\hline Nimesulide & 0.8 & 2.5 & $100 \pm 7$ & $105 \pm 9$ & $80 \pm 9$ & $80 \pm 7$ & $85 \pm 6$ & $90 \pm 4$ \\
\hline Propylparaben & 0.1 & 0.5 & $105 \pm 14$ & $73 \pm 10$ & $80 \pm 7$ & $110 \pm 10$ & $105 \pm 5$ & $80 \pm 7$ \\
\hline Triclocarban & 0.8 & 2.5 & $80 \pm 2$ & $120 \pm 6$ & $97 \pm 5$ & $90 \pm 8$ & $110 \pm 9$ & $85 \pm 5$ \\
\hline Triclosan & 0.8 & 2.5 & $118 \pm 2$ & $120 \pm 8$ & $100 \pm 2$ & $120 \pm 10$ & $105 \pm 9$ & $107 \pm 15$ \\
\hline \multicolumn{9}{|l|}{ Pesticide } \\
\hline Azoxystrobin & 0.1 & 0.5 & $100 \pm 9$ & $120 \pm 8$ & $100 \pm 3$ & $70 \pm 11$ & $80 \pm 8$ & $70 \pm 6$ \\
\hline Carbofuran & 0.1 & 0.5 & $80 \pm 6$ & $75 \pm 9$ & $90 \pm 8$ & $120 \pm 10$ & $85 \pm 3$ & $80 \pm 9$ \\
\hline Cyproconazole & 0.1 & 0.5 & $80 \pm 6$ & $75 \pm 9$ & $90 \pm 8$ & $120 \pm 10$ & $85 \pm 4$ & $80 \pm 11$ \\
\hline Clomazone & 0.1 & 0.5 & $97 \pm 8$ & $120 \pm 4$ & $100 \pm 3$ & $90 \pm 6$ & $98 \pm 3$ & $76 \pm 5$ \\
\hline Dichloran & 0.8 & 2.5 & $100 \pm 7$ & $80 \pm 5$ & $72 \pm 3$ & $100 \pm 4$ & $80 \pm 8$ & $120 \pm 9$ \\
\hline Difenoconazole & 0.8 & 2.5 & $100 \pm 10$ & $120 \pm 15$ & $80 \pm 16$ & $99 \pm 15$ & $120 \pm 8$ & $100 \pm 16$ \\
\hline Diuron & 0.1 & 0.5 & $80 \pm 14$ & $85 \pm 10$ & $70 \pm 9$ & $82 \pm 17$ & $90 \pm 5$ & $92 \pm 9$ \\
\hline Epoxyconazole & 0.1 & 0.5 & $100 \pm 13$ & $120 \pm 12$ & $100 \pm 18$ & $90 \pm 13$ & $95 \pm 8$ & $85 \pm 9$ \\
\hline Fenoxaprop- $p$-ethyl & 0.8 & 2.5 & $100 \pm 8$ & $90 \pm 11$ & $91 \pm 5$ & $95 \pm 10$ & $90 \pm 6$ & $80 \pm 7$ \\
\hline Fipronil & 0.1 & 0.5 & $70 \pm 14$ & $70 \pm 5$ & $90 \pm 10$ & $85 \pm 5$ & $70 \pm 5$ & $100 \pm 6$ \\
\hline Iprodione & 0.1 & 0.5 & $100 \pm 2$ & $120 \pm 6$ & $97 \pm 8$ & $100 \pm 4$ & $120 \pm 10$ & $98 \pm 8$ \\
\hline Irgarol & 0.8 & 2.5 & $70 \pm 16$ & $80 \pm 10$ & $93 \pm 4$ & $70 \pm 3$ & $90 \pm 6$ & $100 \pm 10$ \\
\hline Malathion & 0.8 & 2.5 & $120 \pm 10$ & $104 \pm 15$ & $120 \pm 9$ & $90 \pm 12$ & $75 \pm 10$ & $80 \pm 9$ \\
\hline Penoxsulam & 0.8 & 2.5 & $70 \pm 3$ & $110 \pm 5$ & $120 \pm 15$ & $76 \pm 18$ & $113 \pm 15$ & $120 \pm 10$ \\
\hline Pyraclostrobin & 0.8 & 2.5 & $100 \pm 7$ & $120 \pm 10$ & $95 \pm 6$ & $120 \pm 10$ & $85 \pm 15$ & $100 \pm 12$ \\
\hline Propanil & 0.8 & 2.5 & $120 \pm 13$ & $80 \pm 7$ & $79 \pm 10$ & $118 \pm 10$ & $88 \pm 9$ & $78 \pm 10$ \\
\hline Propiconazole & 0.8 & 2.5 & $120 \pm 16$ & $116 \pm 12$ & $110 \pm 9$ & $116 \pm 14$ & $108 \pm 7$ & $96 \pm 10$ \\
\hline Tebuconazole & 0.8 & 2.5 & $106 \pm 12$ & $72 \pm 14$ & $74 \pm 10$ & $110 \pm 12$ & $90 \pm 9$ & $84 \pm 12$ \\
\hline Trifloxystrobin & 0.8 & 2.5 & $82 \pm 8$ & $100 \pm 11$ & $105 \pm 5$ & $80 \pm 10$ & $107 \pm 8$ & $85 \pm 7$ \\
\hline Diuron- $d_{6}$ & 0.8 & 0.5 & $70 \pm 4$ & & & & & \\
\hline Carbofuran- $d_{3}$ & 0.8 & 0.5 & $100 \pm 3$ & & & & & \\
\hline
\end{tabular}

LOD: limit of detection; LOQ: limit of quantification; R: repeatability; RSD: relative standard deviation; PPCP: pharmaceuticals and personal care products. 

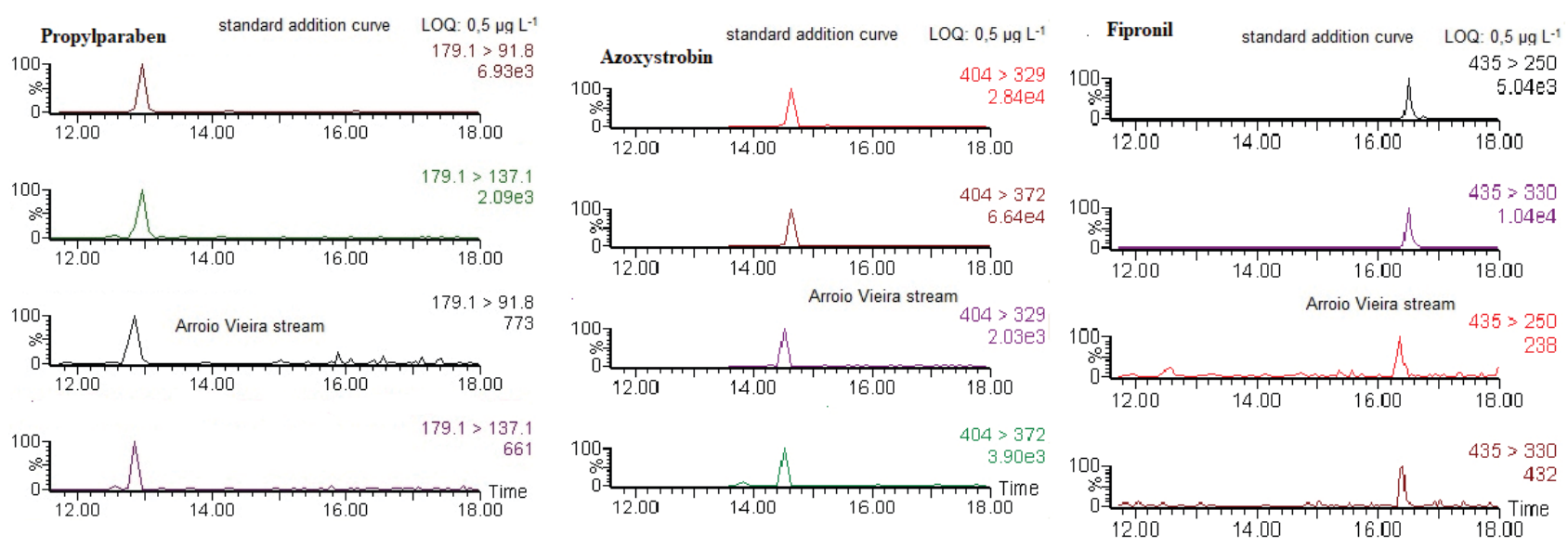

Figure 1. Chromatogram of the analytes in the standard addition curve and in the surface water samples of Arroio Vieira.

Carbofuran- $d_{3}$ and diuron- $d_{6}$ were added in the samples as recovery standards to evaluate the extraction efficiency during sample preparation. One liter of the sample was collected with the aid of a stainless steel mug and stored in an amber glass bottle which had been rinsed with acetone and heated at $100^{\circ} \mathrm{C}$. Before sampling, bottles were rinsed with the sample. Samples were stored at $4{ }^{\circ} \mathrm{C}$ until analysis, which was performed on the same day.

Propylparaben, azoxystrobin and fipronil concentrations were detected below the quantification limit. In Figure 1, the chromatograms of the analytes in the standard addition curve can be observed in concentration respective to their LOQs and in the surface water samples of Arroio Vieira.

\section{Comparison of IL-DLLME with other methods}

The extraction and determination of pesticides and PPCPs in water samples in this study was compared to other methods in Table 3. ${ }^{18,50,52-55}$ As seen in Table 3, extractions using IL-DLLME generally require a temperature between 50-90 ${ }^{\circ} \mathrm{C}$. In temperature-controlled IL-DLLME, the extraction time includes heating and cooling. Thus, this technique has a longer extraction time when compared to traditional IL-DLLME. In some cases, the extraction times are longer than $30 \mathrm{~min}$. The advantages of the method described in this article over the others include shorter extraction times and less energy expenditure because it does not require any special equipment, in contrast to the other aforementioned techniques that require a heating plate or ultrasound. Moreover, the method showed similar accuracy and LOQs to those proposed in other studies. It is noted that all the other methods reported in literature apply IL-DLLME for compounds of the same chemical class, thus this method has never been applied for simultaneous analysis of pesticides and PPCPs in water samples. In conclusion, IL-DLLME is a fast, simple and environmentally friendly method because it uses an ionic liquid, considered a green and non-toxic solvent, as solvent extractor.

\section{Conclusions}

In this study, the determination of 35 PPCPs and pesticides was carried out using $100 \mu \mathrm{L}$ of the extraction solvent $\left[\mathrm{C}_{6} \mathrm{MIM}\right]\left[\mathrm{PF}_{6}\right]$ and $500 \mu \mathrm{L}$ of the disperser solvent methanol and $10 \mathrm{~mL}$ water sample with the $\mathrm{pH}$ adjusted to 4. A simple, efficient and environmentally friendly method, IL-DLLME followed by determination by LC-MS/MS, was developed for simultaneous analysis of pesticides and PPCPs in water samples. In this method, chlorinated solvents commonly used in traditional DLLME are replaced by solvents of low toxicity, thereby reducing the exposure of the analyst to toxic solvents. In comparison to other ILDLLME methods, the method proposed showed advantages such as speed, ease of operation and low cost. Overall, the present study shows, for the first time, that IL-DLLME with LC-MS/MS can be considered an innovative and efficient method for multi-residue extraction and determination in water samples. The method was successfully applied in the extraction and multi-residue determination of pesticides and PPCPs in water samples.

\section{Acknowledgments}

The authors acknowledge the financial support and fellowships granted by the Brazilian agencies CAPES, FINEP, CNPq and FURG. Part of this study was supported by a grant from the Brazilian Agency CNPq/CAPES (process number 552318/2011-6), FAPERGS (process numbers 810-25.51/13-3 and 831-25.51/13-0). E. G. Primel received a productivity research fellowship from the Brazilian Agency CNPq (DT 310517/2012-5). L. C. 
Table 3. Comparison of IL-DLLME with other methods for the determination of compounds in water samples

\begin{tabular}{|c|c|c|c|c|c|c|c|c|c|}
\hline $\begin{array}{l}\text { Extraction } \\
\text { technique }\end{array}$ & Analyte & $\begin{array}{l}\text { Sample } \\
\text { volume }\end{array}$ & $\begin{array}{c}\text { Extraction } \\
\text { solvent (volume) }\end{array}$ & $\begin{array}{l}\text { Extraction } \\
\text { time }\end{array}$ & $\begin{array}{l}\text { Centrifuged } \\
\text { time / min }\end{array}$ & $\begin{array}{c}\text { Accuracy I } \\
\%\end{array}$ & $\begin{array}{c}\text { Precision / } \\
\%\end{array}$ & $\begin{array}{l}\text { LOQ range / } \\
\left(\mu \mathrm{g} \mathrm{L}^{-1}\right)\end{array}$ & Reference \\
\hline IL-TC-DLLME $^{\mathrm{a}}$ & 2 pesticides & $\begin{array}{c}10 \mathrm{~mL} \\
\text { rainwater, } \\
\text { groundwater } \\
\text { and river water }\end{array}$ & $\begin{array}{c}{\left[\mathrm{C}_{6} \mathrm{MIM}\right]\left[\mathrm{PF}_{6}\right]} \\
(50 \mu \mathrm{L})\end{array}$ & $\begin{array}{l}\text { heating at } \\
80{ }^{\circ} \mathrm{C} \text { for } \\
30 \mathrm{~min}\end{array}$ & $20 \mathrm{~min}$ & $88-103$ & $<3$ & $0.2-0.3$ & 18 \\
\hline IL-DLLME $^{b}$ & 4 pesticides & $\begin{array}{c}5 \mathrm{~mL} \text { tap, lake } \\
\text { and fountain } \\
\text { waters }\end{array}$ & $\begin{array}{c}{\left[\mathrm{C}_{6} \mathrm{MIM}\right]\left[\mathrm{PF}_{6}\right]} \\
\quad(40 \mu \mathrm{L})\end{array}$ & & $\begin{array}{l}10 \mathrm{~min} \text { at } \\
4000 \mathrm{rpm}\end{array}$ & $82-106$ & $<10.7$ & $1.7-4.2$ & 52 \\
\hline IL-TC-DLLME $^{\mathrm{a}}$ & $\begin{array}{c}1 \text { pesticide } \\
\text { and } \\
3 \text { metabolites }\end{array}$ & $\begin{array}{l}10 \mathrm{~mL} \text { surface } \\
\text { water sample }\end{array}$ & $\begin{array}{c}\mathrm{C}_{6} \mathrm{MIM}^{\mathrm{MIM}}\left[\mathrm{PF}_{6}\right] \\
(50 \mu \mathrm{L})\end{array}$ & $\begin{array}{l}\text { heating at } \\
75^{\circ} \mathrm{C} \text { for } \\
30 \mathrm{~min} \text {, } \\
\text { ice-water bath } \\
\text { for } 2 \mathrm{~min}\end{array}$ & $\begin{array}{l}15 \mathrm{~min} \text { at } \\
4000 \mathrm{rpm}\end{array}$ & $97-106$ & $<7$ & $0.2-0.4$ & 53 \\
\hline IL-USA-DLLME $^{c}$ & 4 solar filters & $\begin{array}{c}10 \mathrm{~mL} \text { pool } \\
\text { water, tap and } \\
1 \text { river water }\end{array}$ & $\begin{array}{c}\text { [HMIM][FAP }] \\
\quad(20 \mu \mathrm{L})\end{array}$ & $\begin{array}{l}17 \text { min of total } \\
\text { extraction } \\
\text { time, used an } \\
\text { ultrasound } \\
\text { bath and } \\
\text { methanol }\end{array}$ & & $71-118$ & $<6.3$ & $0.6-15$ & 50 \\
\hline IL-DLLME $^{\mathrm{b}}$ & 8 antibiotics & $\begin{array}{c}10 \mathrm{~mL} \\
\text { groundwater } \\
\text { samples }\end{array}$ & $\begin{array}{c}{\left[\mathrm{C}_{8} \mathrm{MIM}\right]\left[\mathrm{PF}_{6}\right]} \\
\quad(52 \mu \mathrm{L})\end{array}$ & & $\begin{array}{l}10 \mathrm{~min} \text { at } \\
4000 \mathrm{rpm}\end{array}$ & $85-107$ & $<9.3$ & $0.003-0.05$ & 54 \\
\hline IL-TC-DLLME $^{\mathrm{a}}$ & 3 pesticides & $\begin{array}{l}10 \mathrm{~mL} \\
\text { rainwater and } \\
\text { underground }\end{array}$ & $\begin{array}{c}{\left[\mathrm{C}_{8} \mathrm{MIM}\right]\left[\mathrm{PF}_{6}\right]} \\
(55 \mu \mathrm{L})\end{array}$ & $\begin{array}{c}30 \text { min over } \\
\text { heating at } \\
90^{\circ} \mathrm{C}\end{array}$ & $\begin{array}{l}20 \mathrm{~min} \text { at } \\
4000 \mathrm{rpm}\end{array}$ & $83-118$ & $<11$ & $0.0015-2.64$ & 55 \\
\hline IL-DLLME $^{\mathrm{b}}$ & $\begin{array}{l}35 \text { pesticides } \\
\text { and PPCPs }\end{array}$ & $\begin{array}{c}10 \mathrm{~mL} \text { surface } \\
\text { sample pH } 4\end{array}$ & $\begin{array}{c}{\left[\mathrm{C}_{6} \mathrm{MIM}\right]\left[\mathrm{PF}_{6}\right]} \\
(100 \mu \mathrm{L})\end{array}$ & & $\begin{array}{l}10 \mathrm{~min} \text { at } \\
4000 \mathrm{rpm}\end{array}$ & $70-120$ & $\leq 18$ & $0.5-2.5$ & this work \\
\hline
\end{tabular}

atemperature-controlled ionic liquid dispersive liquid-liquid microextraction; bionic liquid dispersive liquid-liquid microextraction; cionic liquid-based ultrasound-assisted dispersive liquid-liquid microextraction. LOQ: limit of quantification; PPCPs: pharmaceuticals and personal care products.

Marube received a postdoctoral fellowship supported by PNPD/CAPES.

\section{References}

1. Yang, M.; Xi, X.; Wu, X.; Lu, R.; Zhou, W.; Zhang, S.; Gao, H.; J. Chromatogr. A 2015, 1381, 37.

2. Lv, M.; Sun, Q.; Hu, A.; Hou, L.; Li, J.; Cai, X.; Yu, C.-P.; J. Hazard. Mater. 2014, 280, 696.

3. Farajzadeh, M. A.; Feriduni, B.; Mogaddam, M. R. A.; Talanta 2016, 146, 772 .

4. Weichenthal, S.; Moase, C.; Chan, P.; Environ. Health Perspect. 2010, 118, 1117.

5. Abhilash, P.; Singh, N.; J. Hazard. Mater. 2009, 165, 1.

6. Bu, Q.; Wang, B.; Huang, J.; Deng, S.; Yu, G.; J. Hazard. Mater. 2013, 262, 189.

7. Caldas, S. S.; Rombaldi, C.; Arias, J. L. O.; Marube, L. C.; Primel, E. G.; Talanta 2016, 146, 676.

8. Lee, I.-S.; Lee, S.-H.; Oh, J.-E.; Water Res. 2010, 44, 214.

9. Raab, U.; Preiss, U.; Albrecht, M.; Shahin, N.; Parlar, H.; Fromme, H.; Chemosphere 2008, 72, 87.
10. Ferrer, I.; Thurman, E. M.; J. Chromatogr. B 2012, 1259, 148.

11. Carmona, E.; Andreu, V.; Picó, Y.; Sci. Total Environ. 2014, $484,53$.

12. Homem, V.; Alves, A.; Alves, A.; Santos, L.; Talanta 2016, 148, 84.

13. Martínez, C.; Ramírez, N.; Gómez, V.; Pocurull, E.; Borrull, F.; Talanta 2013, 116, 937.

14. Huang, S.; Zhu, F.; Jiang, R.; Zhou, S.; Zhu, D.; Liu, H.; Ouyang, G.; Talanta 2015, 136, 198.

15. Hu, C.; He, M.; Chen, B.; Hu, B.; J. Chromatogr. A 2015, 1394 , 36.

16. Hu, C.; He, M.; Chen, B.; Hu, B.; J. Chromatogr. A 2013, 1275 , 25.

17. Rezaee, M.; Assadi, Y.; Hosseini, M.-R. M.; Aghaee, E.; Ahmadi, F.; Berijani, S.; J. Chromatogr. A 2006, 1116, 1.

18. Zhou, Q.; Bai, H.; Xie, G.; Xiao, J.; J. Chromatogr. A 2008, 1188, 148.

19. Ravelo-Pérez, L. M.; Hernández-Borges, J.; Herrera-Herrera, A. V.; Rodríguez-Delgado, M. Á.; Anal. Bioanal. Chem. 2009, 395, 2387. 
20. Espino, M.; Fernández, M. Á.; Gomez, F. J.; Silva, M. F.; TrAC, Trends Anal. Chem. 2016, 76, 126.

21. Spietelun, A.; Marcinkowski, Ł.; de la Guardia, M.; Namieśnik, J.; Talanta 2014, 119, 34.

22. Trujillo-Rodríguez, M. J.; Rocío-Bautista, P.; Pino, V.; Afonso, A. M.; TrAC, Trends Anal. Chem. 2013, 51, 87.

23. Suárez, R.; Clavijo, S.; Avivar, J.; Cerdà, V.; Talanta 2016, 148 , 589.

24. Zhang, S.; Dokko, K.; Watanabe, M.; Chem. Sci. 2015, 6, 3684.

25. Liu, Y.; Zhao, E.; Zhu, W.; Gao, H.; Zhou, Z.; J. Chromatogr. A 2009, 1216, 885.

26. Vázquez, M. P.; Vázquez, P. P.; Galera, M. M.; García, M. G.; Anal. Chim. Acta 2012, 748, 20.

27. Zhou, Q.; Bai, H.; Xie, G.; Xiao, J.; J. Chromatogr. A 2008 , 1188, 148.

28. Wang, Z.; Hu, J.; Du, H.; He, S.; Li, Q.; Zhang, H.; J. Pharm. Biomed. Anal. 2016, 125, 178.

29. Caldas, S. S.; Bolzan, C. M.; Guilherme, J. R.; Silveira, M. A. K.; Escarrone, A. L. V.; Primel, E. G.; Environ. Sci. Pollut. Res. 2013, 20, 5855.

30. Celano, R.; Piccinelli, A. L.; Campone, L.; Rastrelli, L.; J. Chromatogr. A 2014, 1355, 26.

31. European Commission Reference Laboratories (EURL); SANTE/11945/2015, Analytical Quality Control and Method Validation Procedures for Pesticides Residues Analysis in Food and Feed; European Commission; DirectorateGeneral for Health and Food Safety: European Union, 2015. Available at http://www.eurl-pesticides.eu/library/docs/ allcrl/AqcGuidance_SANTE_2015_11945.pdf, accessed in December 2017.

32. Instituto Nacional de Metrologia, Normalização e Qualidade Industrial (INMETRO); DOQ-CGCRE-008, Orientação sobre Validação de Métodos Analíticos, revisão 03; INMETRO: Rio de Janeiro, 2010. Available at http://www.inmetro.gov.br/Sidoq/ Arquivos/CGCRE/DOQ/DOQ-CGCRE-8_03.pdf, accessed in December 2017.

33. Economou, A.; Botitsi, H.; Antoniou, S.; Tsipi, D.; J. Chromatogr. A 2009, 1216, 5856.

34. Zhang, J.; Li, M.; Yang, M.; Peng, B.; Li, Y.; Zhou, W.; Gao, H.; Lu, R.; J. Chromatogr. A 2012, 1254, 23.

35. Zhang, J.; Gao, H.; Peng, B.; Li, S.; Zhou, Z.; J. Chromatogr. A 2011, 1218, 6621 .

36. Zhang, H.-F.; Shi, Y.-P.; Talanta 2010, 82, 1010.

37. Zhao, R.-S.; Wang, S.-S.; Cheng, C.-G.; Zhang, L.-L.; Wang, X.; Chromatographia 2011, 73, 793.
38. Ravelo-Pérez, L. M.; Hernández-Borges, J.; Asensio-Ramos, M.; Rodríguez-Delgado, M. Á.; J. Chromatogr. A 2009, 1216, 7336.

39. Liang, P.; Wang, F.; Wan, Q.; Talanta 2013, 105, 57.

40. Tolcha, T.; Merdassa, Y.; Megersa, N.; J. Sep. Sci. 2013, 36, 1119.

41. Wu, J.-W.; Chen, H.-C.; Ding, W.-H.; J. Chromatogr. A 2013 , 1302, 20.

42. Gure, A.; Lara, F. J.; García-Campaña, A. M.; Megersa, N.; del Olmo-Iruela, M.; Food Chem. 2015, 170, 348.

43. Hendriks, G.; Uges, D.; Franke, J.; J. Chromatogr. B 2007, 853, 234.

44. Yao, C.; Li, T.; Twu, P.; Pitner, W. R.; Anderson, J. L.; J. Chromatogr. A 2011, 1218, 1556.

45. Cruz-Vera, M.; Lucena, R.; Cárdenas, S.; Valcárcel, M.; J. Chromatogr. A 2008, 1202, 1.

46. Behbahani, M.; Esrafili, A.; Bagheri, S.; Radfar, S.; Bojdi, M. K.; Bagheri, A.; Measurement 2014, 51, 174.

47. European Union; Council Directive 91/676/EEC of 12 December 1991 Concerning the Protection of Waters against Pollution Caused by Nitrates from Agricultural Sources; Official Journal of the European Communities, 1991, L375. Available at http://eur-lex.europa.eu/legal-content/EN/TXT/PDF/?uri=C ELEX:31991L0676\&from=EN, accessed in December 2017.

48. Ministério da Saúde; Ordinance No. 2,914/2011, Procedure of Control and Surveillance of Water Quality for Human Consumption and its Potability Standards; Diário Oficial da União: Brasília, 2011. Available at http://bvsms.saude.gov. br/bvs/publicacoes/portaria_2914_2011.pdf, accessed in December 2017.

49. Zhao, R.-S.; Wang, X.; Sun, J.; Hu, C.; Wang, X.-K.; Microchim. Acta 2011, 174, 145.

50. Zhang, Y.; Lee, H. K.; Anal. Chim. Acta 2012, 750, 120.

51. Salgueiro-González, N.; Concha-Graña, E.; Turnes-Carou, I.; Muniategui-Lorenzo, S.; López-Mahía, P.; Prada-Rodríguez, D.; J. Chromatogr. A 2012, 1223, 1.

52. Liu, Y.; Zhao, E.; Zhu, W.; Gao, H.; Zhou, Z.; J. Chromatogr. A 2009, 1216, 885 .

53. Bai, H.; Zhou, Q.; Xie, G.; Xiao, J.; Anal. Chim. Acta 2009, 651, 64.

54. Vázquez, M. P.; Vázquez, P. P.; Galera, M. M.; García, M. G.; Anal. Chim. Acta 2012, 748, 20.

55. Zhou, Q.-X.; Gao, Y.-Y.; Chin. Chem. Lett. 2014, 25, 745.

Submitted: September 7, 2017 Published online: December 19, 2017 